\title{
Stable electrical, morphological and optical properties of titanium dioxide nanoparticles affected by annealing temperature
}

\author{
Sh. Nadzirah ${ }^{1}$ (1) Uda Hashim ${ }^{1}$ M. Kashif $^{2} \cdot$ Shahidah Arina Shamsuddin $^{1,3}$
}

Received: 16 November 2015 / Accepted: 15 March 2016

(C) Springer-Verlag Berlin Heidelberg 2016

\begin{abstract}
Different $\mathrm{TiO}_{2}$ synthesization processes give different properties. Most of researches in material studies only focus on the morphological and optical properties of $\mathrm{TiO}_{2}$ while lacking in the effort of achieving stable electrical properties of the material. In engineering, stable electrical properties are vital in order to develop a device. Moreover, current technology needs more nanostructure application to enhance the performance of devices. In this paper, $\mathrm{TiO}_{2}$ nanoparticle was synthesized by sol-gel method using 1:0.1:9 ratios of titanium isopropoxide:acetic acid:ethanol, respectively. This synthesized $\mathrm{TiO}_{2}$ was able to respond in extremely small and consistent electrical reading (nanoampere). This metal oxide is good enough to be used as a material to develop ultra-high sensitive biosensor. Annealing process on the $\mathrm{TiO}_{2}$ film was able to improve its' electrical conductivity. The three layers $\mathrm{TiO}_{2}$ coating were annealed at $400,500,600$ and $700{ }^{\circ} \mathrm{C}$ and the surface morphologies, structural also electro-optical properties were studied using FESEM, XRD, UV-Vis and Keithley 6485 picoammeter. The XRD pattern shows the presence of stable anatase and rutile structures even at low temperature, whereas FESEM shows that annealing
\end{abstract}

Sh. Nadzirah

shnadzirahsaa@gmail.com

Uda Hashim

uda@unimap.edu.my

1 Institute of Nano Electronic Engineering, Universiti Malaysia Perlis (UniMAP), 01000 Kangar, Perlis, Malaysia

2 Department of Electrical and Electronic Engineering, Faculty of Engineering, Universiti Malaysia Sarawak, 94300 Kota Samarahan, Sarawak, Malaysia

3 Nanomaterial Biomedical Diagnostics Research Group, Institute of Nano Electronic Engineering (INEE), University Malaysia Perlis (UniMAP), Kangar, Perlis, Malaysia temperature affects the particle size. The optical band gap of $\mathrm{TiO}_{2}$ thin films decreases from 3.74 to $3.34 \mathrm{eV}$ as the annealing temperature increases. The current-to-voltage characteristics show that the conductivity decreases as the annealing temperature varies from 400 to $700{ }^{\circ} \mathrm{C}$. The output measurements indicated an improvement in electrical properties with annealing temperature.

\section{Introduction}

Titanium dioxide $\left(\mathrm{TiO}_{2}\right)$ or tinania is an n-type semiconductor that can be formed in three different phases, namely, brookite, anatase, and rutile (Ahmadi et al. 2011; Moses Ezhil Raj et al. 2010; Koparde and Cummings 2008; Pradhan et al. 2011). $\mathrm{TiO}_{2}$ has high chemical and temperature stability (Lee et al. 2008). The high resistance of $\mathrm{TiO}_{2}$ towards acid and alkali makes it suitable for artificial bone or tooth fabrication. Given that $\mathrm{TiO}_{2}$ is a biocompatible material, it is safe and non-poisonous in biosensor development. $\mathrm{TiO}_{2}$ can generate non-poisonous $\mathrm{CO}_{2}$ and $\mathrm{H}_{2} \mathrm{O}$ in some inorganic products when organic pollutants are decomposed by light (Lee et al. 2008). These multiple applications are due to its different phase formations, which have their own unique properties, causing $\mathrm{TiO}_{2}$ to gain tremendous attention from researchers. The anatase phase acts as a photocatalyst with different applications, such as water treatment, air treatment, microbial decomposition and pollutant eliminator (Ahmadi et al. 2011). By contrast, the crystal structure of rutile can be applied in pigment coating (Ahmadi et al. 2011) in cars or in the painting industry. Researchers are focusing more on anatase $\mathrm{TiO}_{2}$ because of its wider band gap energy compared with that of rutile $\mathrm{TiO}_{2}$, which is best known for its photocatalytic property. Anatase to rutile phase transformation can be achieved by 